\title{
AVALIAÇÃO DA APRENDIZAGEM NA EDUCAÇÃO ESPECIAL E AS INFLUÊNCIAS DAS POLÍTICAS NACIONAIS
}

\author{
EVALUACIÓN DEL APRENDIZAJE EN LA EDUCACIÓN ESPECIAL Y \\ LAS INFLUENCIAS DE LAS POLITICAS NACIONALES
}

\author{
LEARNING EVALUATION ON SPECIAL EDUCATION \\ UNDER INFLUENCES OF NATIONAL POLICIES
}

\author{
Tania Mara Zancanaro PIECZKOWSKI ${ }^{1}$
}

\begin{abstract}
RESUMO: Avaliação é um tema desafiador e avaliar estudantes com deficiência é ainda mais complexo. Este texto objetiva evidenciar aspectos da avaliação da aprendizagem de estudantes com deficiência, público da educação especial, nos diferentes níveis de ensino e sua relação com as políticas nacionais de avaliação. Está inspirado na Tese de doutorado da autora, especialmente numa das questões de estudo, que tratou da avaliação da aprendizagem de estudantes com deficiência no contexto universitário. São consideradas também, neste artigo, outras pesquisas, as quais investigaram a inclusão na educação básica, de forma que compreender como acontece a avaliação da aprendizagem de estudantes com deficiência na escola inclusiva se constitui o atual problema de investigação. $\mathrm{O}$ material empírico gerado por meio de entrevistas narrativas foi examinado pela perspectiva da análise do discurso, amparada em referenciais foucaultianos. Os estudos apontam para a ambivalência da avaliação no contexto da escola inclusiva, que divulga princípios como temporalidade distinta, respeito à diferença, porém organiza-se, predominantemente, em tempos e espaços fixos para todos. A presença de estudante com deficiência no sistema educacional gera movimento, no sentido de desnaturalizar estruturas padronizadas, o que reverbera nas práticas de avaliação.
\end{abstract}

PALAVRAS-CHAVE: Avaliação. Estudantes com deficiência. Educação inclusiva. Diferença.

RESUMEN: La evaluación es un tema desafiante y evaluar estudiantes con discapacidad es aún más complejo. Este texto objetiva evidenciar aspectos de la evaluación del aprendizaje de estudiantes con discapacidad, público de la educación especial, en los diferentes niveles de enseñanza y su relación con las políticas nacionales de evaluación. Está inspirado en la Tesis de doctorado de la autora, especialmente en una de las cuestiones de estudio, que trató de la evaluación del aprendizaje de estudiantes con discapacidad en el contexto universitario. Son consideradas igualmente en este artículo, otras pesquisas, en las cuales fueron investigadas la inclusión en la educación básica, de manera que comprender como

1 Universidade Comunitária da Região de Chapecó (UNOCHAPECÓ) - BRASIL. Professora e pesquisadora do Programa de Pós-Graduação Stricto Sensu em Educação. Líder do grupo de pesquisa Desigualdades Sociais, Diversidades Socioculturais e Práticas Educativas. ORCID: <http://orcid.org/0000-0002-5257-7747>. E-mail: taniazp@unochapeco.edu.br. 
ocurre la evaluación del aprendizaje de estudiantes con discapacidad en la escuela inclusiva se constituye el actual problema de la investigación. El material empírico generado por medio de entrevistas narrativas fue examinado por la perspectiva del análisis del discurso, amparada en referenciales foucaultianos. Los estudios apuntan para la ambivalencia de la evaluación en el contexto de la escuela inclusiva, que revela principios como temporalidad distinta, respecto a la diferencia, pero se organiza predominantemente, en tiempos y espacios fijos para todos. La presencia de estudiante con discapacidad en el sistema educacional genera movimiento, en el sentido de desnaturalizar estructuras estandarizadas, lo que reverbera en las prácticas de la evaluación.

PALABRAS CLAVE: Evaluación. Estudiantes con discapacidad. Educación inclusiva. Diferencia.

ABSTRACT: Evaluation is a challenging issue and evaluate disabled students is even harder. This paper aims to highlight aspects of learning evaluation of students with disabilities, people assisted by special education, at different levels of education and the relationship with national evaluation policies. It is inspired by the doctoral thesis of the author of this article, especially in the study question about college learning evaluation of disabled students. In this article, researches that investigated inclusion in elementary education are also considered, which target on understanding how the evaluation of disabled students happens in the inclusive schools, the study problem. The empirical data collected by narrative interviews were examined from the perspective of the discourse analysis, supported byfoucaultian references. The studies point to the ambivalence evaluation in the context of inclusive school, which promotes principles such as timing distinction and respect for difference, however, they are predominantly organized in fixed time and space for everyone. Inclusion of students with disabilities in the educational system challenges the environment, denaturing standardized structures, which reverberates in the evaluation practices.

KEYWORDS: Evaluation. Students with disabilities. Inclusive education. Difference.

\section{Introdução}

Este artigo está inspirado na minha tese de doutorado em educação, inserida na linha de pesquisa educação especial, que tratou, dentre as questões de pesquisa, da avaliação da aprendizagem de estudantes com deficiência no contexto universitário. Este texto parte da questão de estudo referida e amplia o enfoque dado na tese, relacionando aspectos da avaliação de estudantes com deficiência nos diferentes níveis de ensino às políticas nacionais de avaliação. São considerados, neste artigo, também conhecimentos elaborados a partir de outras pesquisas, pelas quais fui responsável ou atuei como professora orientadora em cursos de graduação e pós-graduação lato e stricto sensu, que investigaram a inclusão escolar de pessoas com deficiência. Desses 
estudos, o recorte é relativo à avaliação, com o objetivo de compreender como acontece a avaliação de estudantes com deficiência e como os docentes são subjetivados pelos discursos da inclusão e pelas políticas de avaliação.

A pesquisa para a tese analisou os discursos de dez docentes, atuantes com estudantes surdos, cegos/baixa visão ou com deficiência física, vinculados a duas universidades, uma pública e uma comunitária, localizadas no estado de Santa Catarina. Cinco professores atuaram na instituição pública e cinco na comunitária. Tratam-se de professores com trajetórias na docência entre dois anos e meio e 25 anos, com formação acadêmica distinta e atuantes em vários cursos de graduação. A definiçãa dos sujeitos da pesquisa aconteceu junto aos setores institucionais que registram a presença de estudantes com deficiência.

Após a aprovação do projeto de pesquisa pelo Comitê de Ética ${ }^{2}$, foi gerado material empírico por meio de entrevistas narrativas, gravadas, transcritas e examinadas pela perspectiva da análise do discurso, amparada em referenciais foucaultianos. As narrativas foram organizadas em agrupamentos temáticos, considerando a recorrência e a relevância das falas. Fischer (2001), amparada em Foucault, salienta que para analisarmos os discursos, precisamos recusar as fáceis interpretações, a busca insistente do sentido último ou do sentido oculto das coisas e que, para Foucault,

[...] nada há por trás das cortinas, nem sob o chão que pisamos. Há enunciados e relações, que o próprio discurso põe em funcionamento. Analisar o discurso seria dar conta exatamente disso: de relações históricas, de práticas muito concretas, que estão 'vivas' nos discursos (FISCHER, 2001, p. 198-199).

A inclusão de estudantes com deficiência é um tema que tem conquistado crescente importância no cenário educacional brasileiro na contemporaneidade. A matrícula desse público na educação básica aumentou especialmente nas últimas duas décadas, resultado das políticas de inclusão. A ampliação do acesso de estudantes com deficiência na educação básica reverbera no aumento da matrícula desses estudantes também na educação superior. De acordo com o Censo da Educação Superior 2013 (BRASIL/INEP, 2015), observa-se um crescimento significativo de 590,78\% no número de estudantes com deficiência matriculados na educação superior em dez anos: em 2003 eram 5.078; em 2011 eram 23.250 e em 2013, 29.034. Porém, se adotado como parâmetro o total de estudantes matriculados na educação superior, que é 7,3

2 As abordagens e os instrumentos metodológicos utilizados obedeceram aos procedimentos éticos estabelecidos para a pesquisa científica em Ciências Humanas. 
milhões, fica perceptível o baixo percentual, de apenas $0,41 \%$ do total de matrículas, especialmente se compararmos ao número de pessoas com deficiência no Brasil, que, conforme o Censo Demográfico 2010, é de 45.606 .048 milhões (IBGE, 2012).

\section{A avaliação no contexto da inclusão escolar de estudantes com deficiência}

Avaliação é um tema desafiador e avaliar estudantes com deficiência é ainda mais complexo, especialmente num cenário nacional em que ganham evidência as avaliações em larga escala, que tendem a padronizar processos, o que se contrapõe à lógica da diferença.

Apesar dos discursos em torno das políticas de inclusão difundirem a colaboração, a resolução de problemas e o trabalho coletivo, o reconhecimento da diferença, ainda são muito presentes as tecnologias individualizantes, que segundo Gallo (2004) nos parecem naturais, mas são recentes. Um olhar histórico nos revela que para a Educação poder cientificizar-se com a Pedagogia, era necessário mais do que controlar os alunos,

[...] também era necessário poder quantificá-los em seu processo de aprendizagem, para ordená-los através da máthêsis e da taxinomia. Uma das táticas instrumentais mais eficazes foi fornecida exatamente através da tecnologia do exame (GALLO, 2004, p. 92).

Foucault salienta as tecnologias de disciplinamento, vigilância, normalização e controle, utilizadas pelas instituições modernas, especialmente no século XVIII, que resultaram, dentre outras manifestações, na quantificação e hierarquização dos estudantes, práticas facilmente encontradas nos cenários escolares.

E pelo jogo dessa quantificação, dessa circulação dos adiantamentos e das dívidas, graças aos cálculos permanentes das notas a mais ou a menos, os aparelhos disciplinares hierarquizam, numa relação mútua os 'bons' e os 'maus' indivíduos (FOUCAULT, 1999, p. 151).

Assim, o exame se consolidou como uma estratégia de controle e vigilância, de acesso à intimidade do estudante, tanto no aspecto pedagógico, quanto no aspecto político. Gallo (2004, p. 93), afirma que "[...] este instrumento declarado de poder, acaba por constituir-se na tecnologia mesma da transmissão do saber, pois é através do exame que o processo de ensino-aprendizagem é verificado, controlado, planejado e replanejado, etc". 
Beyer (2013), ao evidenciar os processos de inclusão e avaliação, salienta distintas concepções relacionados a diferentes paradigmas, entre eles: a) cínico-médico: a deficiência é concebida como uma situação individualizada e o trabalho educacional é definido por orientação terapêutica; b) sistêmico: a deficiência do estudante é avaliada com base nas demandas impostas pelo currículo. "Assim, aos alunos cujo insucesso na aprendizagem signifique a impossibilidade na progressão na escola regular, outras alternativas serão oferecidas" (BEYER, 2013, p. 92), a exemplo de escolas especiais; c) sociológico: a deficiência é definida como processo de atribuição social, no qual o olhar do indivíduo é deslocado para o grupo social, ou seja, a reação social produz o agravamento ou amenização da deficiência; e d) crítico-materialista: a deficiência é compreendida como resultado da incapacidade produtiva do indivíduo. Para o autor,

\begin{abstract}
Enquanto o primeiro paradigma faz sobressair a condição clínica, como determinante nas limitações individuais, o terceiro sobreleva as reações sociais diante da condição individual. Enquanto o segundo paradigma mostra a dinâmica entre os sistemas escolares (regular e especial) como forma social de lidar com o sujeito (aluno) que "fracassa", o quarto busca desvelar o conceito de deficiência como resultante de uma sociedade de classes que supervaloriza a produção e aquisição de bens de consumo (BEYER, 2013, p. 92).
\end{abstract}

A avaliação da aprendizagem pode ser significada de diferentes formas, de acordo com as concepções de quem avalia e do contexto no qual ela é aplicada: para incluir ou excluir; para diagnosticar melhores caminhos ou para classificar o sujeito com as marcas da incompetência, da incapacidade, da deficiência; para emancipar e motivar o crescimento pessoal ou para culpabilizar. Certamente, entre "isso ou aquilo", existem muitos matizes.

Chizzotti (2016, p. 568) afirma que "mais que uma medida objetiva, um 'termômetro' do aprendizado do aluno, a avaliação é sempre um juízo de valor e, por mais que se ampare em suportes quantificados, está impregnada da inevitável subjetividade e preferência do professor". Ao tensionar o processo de avaliação da aprendizagem, o autor alerta para o poder da avaliação que pode "abrir as sendas de um horizonte virtuoso para aprender, criar, inventar ou provocar um desastre existencial na interação educacional, que se estende pela vida”. (2016, p. 563).

Investigações realizadas permitiram constatar que muitos professores, subjetivados pelas políticas de inclusão, vivem conflitos em relação à avaliação da aprendizagem de estudantes com deficiência, possivelmente pelo receio de que recaia 
sobre eles a suspeita da incompetência ou pela influência de concepções históricas que fazem olhar para esses estudantes como sujeitos frágeis, desprotegidos. Sem saber como fazer, muitos classificam seus estudantes com deficiência (especialmente a deficiência intelectual) com nota sete, sem polemizar a escola e a inclusão, ou seja, atribuem o mínimo para aprovar e, dessa forma, tanto os professores como esses estudantes se tornam “invisíveis".

A inclusão comemorada como estratégia de socialização alterou uma cultura naturalizada da segregação, da separação. Porém, atualmente, é necessário garantir o direito de aprendizagem de todas as pessoas.

A complexidade da avaliação de estudantes com deficiência já foi expressa por Itard, médico francês que viveu de 1774 a 1838 e é considerado pioneiro na educação especial. No período de 1801 a 1806, escreveu relatórios detalhados acerca da experiência de educar um menino selvagem, encontrado em uma floresta no Sul da França no ano de 1800, com aproximadamente 12 anos de idade, denominado Victor do Aveyron. No preâmbulo da carta enviada ao Ministro do Interior da França, relatando sua experiência, que foi financiada pelo governo francês, Itard escreve:

Para expressar o estado atual do Selvagem do Aveyron, seria necessário lembrar seu estado passado. Esse rapaz, para ser julgado sadiamente, só deve ser comparado a si mesmo. Aproximado a um adolescente da mesma idade, não é mais que um ser desgracioso, rebotalho da natureza, como o foi da sociedade. Mas, se nos atemos aos dois termos de comparação oferecidos pelo estado passado e o estado presente do jovem Victor, ficamos surpreendidos com o espaço imenso que os separa; e podemos indagar se Victor não difere mais do Selvagem do Aveyron, em sua chegada a Paris, do que difere dos outros indivíduos de sua idade e de sua espécie (ITARD, 2000, p. 184).

Essa passagem do relatório de Itard, somada a pesquisas atuais, mostra a inquietação vivida por professores que são chamados a incluir os estudantes com deficiência nas turmas e a pressão para atender às expectativas padronizadas de formação em cada etapa.

\section{Narrativas e ambivalência da avaliação de estudantes com deficiência}

Estudos e vivências como gestora universitária me auxiliaram a compreender que, na educação superior, reprovar estudantes sem deficiência, para muitos professores, é fácil, é "natural", especialmente em alguns cursos da área de ciências exatas. 
Participei de diálogos com professores de disciplinas nas quais os índices de reprovação no semestre são expressos em percentuais de $60 \%$ a $80 \%$. Para alguns, a reprovação é naturalizada e justificada pela falência da educação básica; pela omissão das famílias em definir limites na educação dos filhos, o que repercute na universidade; porque os estudantes "de hoje" são adeptos às futilidades e facilidades da vida ou porque trabalham o dia todo e, cansados, não têm motivação para estudar à noite; entre outras causas. A sensação é de que nada há por fazer para esse percentual de estudantes, que representa a maioria nas turmas das disciplinas em questão.

Porém, quando o estudante é concebido como frágil, desprotegido ou deficiente, o professor entra em conflito, e aprovar parece ser resultado do "não saber como agir". Os professores são subjetivados pelos discursos da inclusão difundidos pela mídia, pelas leis e decretos, dentre outros dispositivos que promovem a ideia de respeito à diferença vista como essencialmente boa, que produz uma sociedade mais acolhedora. Esse jeito de conceber a sociedade e a educação gera conflitos diante de perspectivas seletivas e excludentes ditadas pela sociedade neoliberal. Algumas narrativas explicitam a inquietação docente diante do desejo de incluir, quando há dúvidas do que é fazer isso, numa sociedade que quer resultados e exclui quem não os obtém da forma padronizada.

Para ilustrar as afirmativas que faço, evidencio, a seguir, a narrativa da Docente $3^{3}$, participante da pesquisa para a tese de doutorado, com vinte anos de atuação como professora e gestora na educação superior. Neste artigo, destaco apenas a manifestação de um dos sujeitos da pesquisa (Docente 3), que sintetiza discursos recorrentes entre os entrevistados, no que se refere ao tema abordado. Nas narrativas destacadas, algumas vezes a Docente 3 refere suas experiências de forma genérica e noutras faz referência a vivências pedagógicas específicas. No primeiro registro destacado, narra:

Olha, chegou um momento que eu aprovei, tenho dúvidas se isso foi bom ou não foi bom para esses alunos. Vai ter professor que provavelmente vai dizer para ti: - olha, melhor que nem tivesse passado por aqui. Então, a gente sempre discute, nas nossas reuniões, o caso do fulano: como abordar, quais são as dificuldades, quais encaminhamentos devem ser dados à avaliação. Até porque, são casos que vem para a coordenação e, enquanto coordenação, você tem que discutir na coletividade. Ou o aluno te procura e diz: tal professor me reprovou; o professor fala e eu não consigo escutar (Docente 3).

${ }^{3} \mathrm{O}$ número 3 indica a ordem de participação nas entrevistas, e foi a opção adotada para fazer referência a cada participante. 
A narrativa revela a complexidade da inclusão quando ela pressupõe ações bilaterais, ou seja, não basta somente o estudante se adequar ao contexto. Perguntei à docente se teve oportunidade de aprender acerca do processo de escrita de pessoas com deficiência auditiva (referência feita na sua fala), de suas especificidades na forma de expressar o pensamento, o que demanda uma forma distinta de avaliar as produções. A mesma afirmou:

Francamente, nem sei se tem alguma, nunca li nada sobre isso, se a pessoa com deficiência auditiva pode apresentar tal potencialidade, tal dificuldade na produção escrita. Nem sei se existe isso. Nem passou isso pela cabeça. (Docente 3).

Na continuidade de nosso diálogo, questionei acerca das demandas de adaptação ao currículo, das práticas de avaliação da aprendizagem, da necessidade de adoção de tecnologias assistivas ou de outras organizações do material didático e do planejamento da aula para a turma na qual a estudante com deficiência auditiva está matriculada.

Na verdade, eu acho que pensava na aula de uma maneira geral. Eu tentava, de alguma forma, fazer diferente. Eu pensava assim: será que ela está entendendo? Alguma coisa ela até entende porque eu pegava muito pela avaliação escrita. Eu acho que com a aluna surda não era diferente, eu preparava a aula e tentava falar mais alto, pegava muito pela questão da própria avaliação. [...] Eu acho que, sinceramente, a gente quase que tenta adaptar aquele aluno, entendeu? Tenta adaptar. Olha, eu não vou mudar o conteúdo. Eu vou falar um pouco mais alto. Fique aqui na minha frente. Eu vou tentar, ainda que esquecesse muito, vou tentar falar de frente para ti. Então, na verdade é uma coisa, muito mais uma coisa do aluno ter que se adaptar, do que eu pensar o que um aluno desses traz de demanda. Eu acho que demanda daí um trabalho que é mais do que um professor só na sala de aula.

Ao mesmo tempo em que a professora verbalizava suas práticas, manifestava refletir sobre elas. A diferença gera inquietação entre a necessidade de "acolher" o estudante com deficiência "incluído" nas turmas e a pressão para atender às expectativas padronizadas de formação em cada etapa, em cada curso de graduação, cujo Projeto Pedagógico, inspirado nas Diretrizes Curriculares Nacionais, indica determinado perfil de egresso para a profissão. A deficiência se caracteriza pela diferença e, portanto, é difícil colocá-la na lógica da categorização, da classificação, da taxonomia, da normalização, tão presentes na escola.

Lopes (2009) ampara-se em Canguilhem, Foucault e Ewald para afirmar a necessidade de classificação, ordenamento, comparação e hierarquização presente na 
norma, a qual opera no sentido "[...] de incluir todos segundo determinados critérios que são construídos no interior e a partir dos grupos sociais. Prescritivamente, ela age na homogeneização das pessoas; ela age na definição de um modelo geral prévio [...]" (LOPES, 2009, p. 159). Segundo a autora,

Nas operações de normalização - que implicam tanto trazer os desviantes para a área da normalidade, quanto naturalizar a presença de tais desviantes no contexto social onde circulam - devem ser minimizadas certas marcas, certos traços e certos impedimentos de distintas ordens. Para isso, vê-se a criação, por parte do Estado, de estratégias políticas que visam à normalização das irregularidades presentes na população. Entre as estratégias criadas para que a normalidade se estabeleça dentro de quadros nos quais surge a ameaça do perigo, é possível citar a criação de políticas de assistência e de políticas de inclusão social e educacional, entre outras. Ambas, ao fim e ao cabo, podem ser vistas como ações inclusivas que visam a trazer para a normalidade partes da população ameaçadas pela miséria, pela doença, pela deficiência, pela falta da previdência, pela falta da escola, etc. (LOPES, 2009, p. 159).

Parece-me que nos últimos anos, na educação especial, surgiu uma nova categoria: das pessoas com deficiência que chegam e das que não chegam à universidade, como se a educação superior representasse uma certa forma de normalizar a deficiência. O sistema de ensino, nesse contexto, funciona como um mecanismo normatizador e normalizador. Os discursos em torno das políticas de inclusão se materializam nas pedagogias que colocam em circulação determinados regimes de verdade amparados no direito à igualdade, aqui entendida como garantia de acesso para todos, mesmo que a inclusão seja excludente. Nesse sentido, Veiga-Neto e Lopes (2007, p. 947) salientam que, da maneira como as políticas de inclusão vêm sendo formuladas e executadas no Brasil, "parecem ignorar a própria diferença. Assim, ao invés de promoverem uma educação para todos, elas correm o risco de realizar uma inclusão excludente das diferenças" (VEIGA-NETO; LOPES, 2007, p. 947).

A Docente 3 explicita preocupação com a inclusão excludente, ao afirmar que a inserção de estudantes com deficiência na educação superior, o seu ingresso e/ou a sua matrícula, não é garantia de êxito no processo.

Porque o ensino superior é processual, é um processo como é para todos os demais. Não garante que alguém faça uma faculdade de engenharia e se torne engenheiro. Esses alunos com deficiência têm mais dificuldade, apesar do mercado de trabalho requerer em função da lei de cotas. Acho que isso é uma coisa boa. Uma outra questão 
que eu percebi, no caso da estudante $F^{4}$, eu peguei no sétimo período e na verdade a turma já estava cansada dela, então, eu sentia isso. Mas eu sei que em períodos anteriores a turma assumiu ela, a turma também desresponsabilizava ela. Ela era a mascote da turma. Então, a turma levava ela para cima e para baixo, a turma ajudava a fazer trabalhos. Na verdade, ela não assumiu sozinha a responsabilidade pela formação dela. A turma assumiu. Era uma turma relativamente pequena, a grande maioria se dava muito bem ali. Então, quando eu reprovei ela, para tu teres uma ideia, eu não tive que dar satisfação só para ela, veio a turma me questionar como é que eu tive coragem de reprová-la. Como é que eu tive coragem de reprová-la? (Docente $3)$.

Subjetividades inclusivas pautadas na caridade, na benevolência atravessam a prática avaliativa quando o sujeito a ser avaliado é concebido como frágil.

Com a estudante $G^{5}$, foi bem complicado. Tanto é que a gente começou com um processo de reprovação: reprovou no estágio, foi reprovando aqui, foi reprovando ali, nem sei se ela retorna, ela não tem vindo ao curso. O que eu acho que é outra coisa que tem que ficar alerta. Tudo bem ser solidário, auxiliar, ter pena, porque também acontece isso. [...] só que você não estimulou a autonomia de maneira nenhuma, vai estimular muito mais a dependência (Docente 3 ).

Nesse sentido, Veiga-Neto alerta para a ambivalência da inclusão, que se manifesta quando ela própria é capaz de gerar exclusão. "Colocamos o outro para dentro de um espaço comum - concreto ou simbólico, pouco importa - para que se garantam saberes sobre esse outro e desde que esse outro continue a ser "um outro" (VEIGANETO, 2008, p. 17).

Na esfera da educação básica, a Política Nacional de Educação Especial na Perspectiva da Educação Inclusiva (BRASIL, 2008) orienta que todas as crianças devem estar matriculadas nas escolas regulares, portanto, sujeitas às políticas nacionais de avaliação. Tenho constatado, também nesse nível de ensino, o conflito que algumas escolas e professores enfrentam no momento de avaliar as crianças com deficiência, especialmente as que apresentam deficiência intelectual e que, na minha percepção, são as que mais se distanciam do modelo rígido, fixo, que a escola apresenta. Concordo com o destaque que apresento a seguir, excerto do texto Educação Inclusiva: Atendimento Educacional Especializado para a Deficiência mental:

${ }^{4}$ Estudante com deficiência auditiva, que não utiliza Língua Brasileira de Sinais (Libras), esforça-se para fazer leitura labial e oralizar, embora sua vocalização seja percebida com dificuldades pelos seus interlocutores.

${ }^{5}$ Estudante com deficiência física manifestada em dificuldades na oralização e nos movimentos. 
A deficiência mental coloca em xeque a função primordial da escola comum que é a produção do conhecimento, pois o aluno com essa deficiência tem uma maneira própria de lidar com o saber que, invariavelmente não corresponde ao ideal da escola. Na verdade, não corresponder ao esperado pode acontecer com todo e qualquer aluno, mas os alunos com deficiência mental denunciam a impossibilidade de atingir esse ideal de forma tácita. Eles não permitem que a escola dissimule essa verdade. As outras deficiências não abalam tanto a escola comum, pois não tocam no cerne e no motivo da sua urgente transformação: entender a produção do conhecimento acadêmico como uma conquista individual. (BRASIL, 2005, p. 12).

A inclusão de crianças com deficiência pode ser uma possibilidade de tensionar a estrutura cristalizada da escola, sem que recaia sobre os professores, individualmente, a suspeita da incompetência profissional e sobre as pessoas com deficiência a pressão de se adequar ao leito de Procusto dos espartanos (AMARAL, 1994, p. 43-44), narrado em uma lenda que, em nossos dias, me sugere uma analogia com o sistema escolar. Para adaptar-se ao leito, corta-se o que sobra em alguns (estudantes com altas habilidades, por exemplo) e a aumenta-se o que falta em outros, de forma que todos assumam as medidas do leito de ferro.

A universidade também tem recebido estudantes com deficiência intelectual, cujos históricos escolares da educação básica registram predominantemente notas sete, o mínimo para aprovar e que revelam, também, a insegurança da escola em avaliá-los. O que a universidade consegue oferecer para estudantes com limitações acentuadas na escrita, na interpretação, na resolução dos desafios do cotidiano? O que muda na docência com a experiência de atuar com estudantes com deficiência? A Docente 3 expressa:

Eu acho que é um grande desafio. Eu acho que essa inquietação, que é permanente, de alguma forma te movimenta. Se ela não te movimenta tanto na ação, ela te movimenta pelo pensamento. Eu acho que isso já é um passo, pelo menos. Muda essa coisa de você "cair a ficha" que você tem um desafio e que esse desafio tem que ser enfrentado.

Atuar com estudantes com deficiência possibilita a desnaturalização da inclusão como se fosse algo dado, natural, ou seja, mera inserção. Incluir pressupõe aprender com a diferença, transformar e ser transformado. O movimento pela inclusão amparouse na ideia de confronto e aprendizagem mútua.

Confronto no sentido de fazer com que ambos os indivíduos, os ditos 'normais' e os 'especiais' encarem-se uns aos outros no convívio diário na escola, repartições e comunidade. Aprendizagem no sentido 
de que tal confronto origina a modificação da percepção que ambos os grupos possuem a respeito um do outro (SANTOS, 1995, p. 24).

Trata-se da ideia de que o desconforto inicial provoca novas possibilidades de organização nos espaços físicos, nas atitudes, no uso de recursos didático-pedagógicos, na percepção das formas de aprender e ser. Mesmo assim, há um vácuo criado entre as políticas de inclusão e o papel que a sociedade atribui à escola/universidade, o que tem gerado receios e dúvidas por parte dos professores. O processo de avaliação evidencia alguns paradoxos escolares e sociais, pois sendo ele predominantemente classificatório, hierarquizante, gera conflito diante de subjetividades produzidas pela lógica da inclusão, que valorizam a solidariedade, a aprendizagem mútua, o reconhecimento da diferença.

\section{Avaliações de larga escala no cenário brasileiro}

Desde a década de 1990, por iniciativa do Ministério da Educação (MEC), um novo elemento se incorpora à avaliação educacional. Refiro-me às avaliações externas, também denominadas de avaliações em larga escala. Foi criado, no início dos anos 1990, o Sistema de Avaliação da Educação Básica (Saeb), do qual derivaram três avaliações externas em larga escala. Informações disponíveis no site do INEP, indicam as três avaliações, evidenciando que:

Em 2005 o Saeb foi reestruturado pela Portaria Ministerial $n^{\circ}$ 931, de 21 de março de 2005. O sistema passou a ser composto por duas avaliações: Avaliação Nacional da Educação Básica (Aneb) e Avaliação Nacional do Rendimento Escolar (Anresc), conhecida como Prova Brasil. A Aneb manteve os procedimentos da avaliação amostral (atendendo aos critérios estatísticos de no mínimo 10 estudantes por turma) das redes públicas e privadas, com foco na gestão da educação básica que até então vinha sendo realizada no Saeb. A Anresc (Prova Brasil) passou a avaliar de forma censitária as escolas que atendessem aos critérios de no mínimo 30 estudantes matriculados na última etapa dos anos iniciais ( $4^{\mathrm{a}}$ série $/ 5^{\circ}$ ano) ou dos anos finais $\left(8^{\mathrm{a}} \mathrm{série} / 9^{\circ}\right.$ ano) do Ensino Fundamental escolas públicas, permitindo gerar resultados por escola. [...] Na edição de 2013 a Avaliação Nacional da Alfabetização (ANA), prevista no Pacto Nacional pela Alfabetização na Idade Certa - PNAIC, passou a compor o Saeb a partir da divulgação da portaria $n^{\circ} 482$, de 7 de junho de 2013. (INEP, 2017).

Para a avaliação do desempenho do estudante ao fim da educação básica foi criado em 1998 o Exame Nacional do Ensino Médio (Enem). A partir de 2009 o Enem passou a ser adotado como mecanismo de seleção para o ingresso no ensino superior e 
para acesso a programas oferecidos pelo governo federal, a exemplo do Programa Universidade para Todos - ProUni.

No que se refere à avaliação dos cursos de graduação, o Exame Nacional de Desempenho dos Estudantes (Enade), considerado um dos pilares da avaliação do Sistema Nacional de Avaliação da Educação Superior (SINAES), foi criado pela Lei nº. 10.861, de 14 de abril de 2004. O SINAES é composto, ainda, pelos processos de Avaliação de Cursos de Graduação e de Avaliação Institucional que, junto com o Enade, formam o conjunto de indicadores que avaliam os cursos e as Instituições de Educação Superior (IES) de todo o Brasil.

O Pacto Nacional pela Alfabetização na Idade Certa - PNAIC, instituído pela Portaria $\mathrm{n}^{\circ} 867$, de 4 de julho de 2012, (BRASIL, 2012) propõe assegurar que todas as crianças estejam alfabetizadas até os oito anos de idade, ao final do $3^{\circ}$ ano do ensino fundamental. Da mesma forma, a Meta 5 do Plano Nacional de Educação, Lei $n^{\circ} 13.005$ de 25 de junho de 2014 (BRASIL, 2014a), prevê "alfabetizar todas as crianças, no máximo, até o final do $3^{\circ}$ (terceiro) ano do ensino fundamental". Questiono essa meta, por entender que ela desconsidera algumas crianças com acentuada deficiência intelectual, que poderão aprender muitas coisas, mas não a leitura e escrita (pelo menos não nos tempos indicados). Saliento que não se trata de pessimismo nem de descrédito na possibilidade de aprendizagem de toda e qualquer criança. Acredito que todas as crianças aprendem, porém, não necessariamente as mesmas coisas nos mesmos tempos. Existem crianças com acentuadas deficiências e que me parecem estar excluídas do “todas as crianças" citado na meta 5 do Plano Nacional de Educação. Como serão avaliadas pela escola? Comparadas a si mesmas ou com outras crianças da mesma faixa etária?

Na lógica da inclusão, com a produção de subjetividades que atendam a esse imperativo, passa-se a operar com o sujeito desejável às regras do neoliberalismo, que é aquele passível de transformação, de autoinvestimento, o sujeito empreendedor e consumidor. A subjetividade inclusiva determina que quando o sujeito é limitado na construção desses atributos por si próprio, deverá ser assumido pelo outro, no caso, pela escola, pela universidade e pelo docente. Mas, como ser inclusivo numa sociedade competitiva? Concordo com Estrela quando afirma que esses princípios contraditórios podem abalar a identidade das universidades e dos docentes e criam dilemas éticos, sobretudo no campo da avaliação, de como manter os padrões habituais de exigência e flexibilização movidos pelos efeitos de uma subjetividade inclusiva. "É, pois, o possível 
conflito entre justiça como equidade e justiça como igualdade que agudiza as oposições entre rigor e objectividade da avaliação versus benevolência e subjectividade" (ESTRELA, 2010, p. 23).

Nesse sentido, também Menezes se manifesta afirmando que a governamentalidade neoliberal pressupõe relações de concorrência, resultando na percepção do outro como potencial competidor. "E então, considerando que uma das características das subjetividades que eu nomeio como inclusivas é exatamente desejar ocupar-se com o outro, como pensar em subjetividades que precisam ser inclusivas na lógica da concorrência?" (MENEZES, 2011, p. 175).

Tiffin e Rajasingham (2007) amparam-se em Hanna para evidenciar a teia avaliativa em que estão inseridas as universidades de hoje, submetidas à avaliação de diferentes segmentos da sociedade, como os alunos, os governos, os empregadores, as agências de crédito e a mídia, na expectativa de resultados objetivos. A rede de avaliação na qual as instituições de educação superior brasileiras foram capturadas, força-as a assumir um padrão de conduta que esteja de acordo com os paradigmas do Estado. O discurso da mídia, especialmente, se mostra potente na construção de subjetividades que definem e julgam as instituições como detentoras de qualidade ou sem qualidade. Basta acompanhar os períodos de divulgação midiática dos resultados do Enade/CPC $6 / \mathrm{IGC}^{7}$, que funcionam, para o Estado, como indicadores de avaliação e qualidade, para perceber a repercussão causada na sociedade.

Cunha (2005) sinaliza as modificações no relacionamento entre o Estado, a universidade e a sociedade.

$\mathrm{Na}$ conjuntura atual, na qual o Estado neoliberal vem definindo políticas educativas identificadas com a base econômica de produção, é fácil observar como o pilar da regulação assume muito mais alto prestígio do que o da emancipação. São eles os definidores de prêmios objetivos e simbólicos que valorizam a docência universitária e reconfiguram a profissionalidade dos professores, definindo o que é um professor de sucesso (CUNHA, 2005, p. 81).

As instituições de educação superior são avaliadas para receber credenciamento ou recredenciamento. O Instrumento de Avaliação Institucional Externa, que subsidia os atos de credenciamento, recredenciamento e transformação de organização acadêmica (presencial), das Instituições de Educação Superior, publicado em agosto de 2014 pelo

${ }^{6}$ Conceito preliminar de Curso.

${ }^{7}$ Índice Geral de cursos. 
Ministério da Educação (BRASIL, 2014b), apresenta alteração nos requisitos legais e normativos. Esses requisitos são regulatórios e seu atendimento é obrigatório. O instrumento apresenta 18 dispositivos legais/normativos e dois deles dizem respeito à inclusão/acessibilidade de pessoas com deficiência ou mobilidade reduzida e com Transtorno do Espectro Autista. Tratam-se dos dispositivos legais número quatro e cinco, este inserido na última versão do instrumento.

Além das instituições, os cursos de graduação também são avaliados por comissões distintas. $\mathrm{O}$ "Instrumento de avaliação de cursos de graduação presencial e a distância”, publicado (atualizado) em agosto de 2015 pelo Ministério da Educação (BRASIL, INEP, 2015), apresenta alteração nos requisitos legais e normativos. Esses requisitos são regulatórios e seu atendimento é obrigatório. O instrumento apresenta 17 dispositivos legais/normativos e três deles são relacionados à inclusão/acessibilidade de pessoas com deficiência ou mobilidade reduzida e com Transtorno do Espectro Autista (TEA).

No glossário que compõe o referido instrumento de avaliação, dos 73 indicados, cinco termos são relativos à acessibilidade a pessoas com deficiência, mobilidade reduzida ou necessidades educacionais especiais: acessibilidade arquitetônica; acessibilidade atitudinal; acessibilidade pedagógica; acessibilidade nas comunicações e acessibilidade digital.

Faço esses registros para evidenciar a relevância da inclusão e acessibilidade no contexto avaliativo e regulatório na educação superior. A evidência à educação inclusiva, à acessibilidade nos instrumentos de avaliação, pode nos sugerir a opção por uma sociedade democrática e inclusiva. Contudo, Pieczkowski (2014) afirma que ao mesmo tempo em que o apelo do Estado é para instituições e professores inclusivos, as avaliações oficiais valorizam indicadores padronizados com foco nos resultados e as instituições são comparadas, gerando ambientes competitivos.

Para observar essa afirmação, basta estar atento à visibilidade das mídias quando da publicação dos resultados do Enade. O ranqueamento entre as instituições de educação superior parece ser estimulado pela mídia e os números muitas vezes são tomados de forma descontextualizada. Da mesma forma, as escolas de educação básica exibem painéis em frente às suas instalações ou em pontos estratégicos das cidades divulgando seus índices de desempenho (desde que tenham sido positivos). O princípio da inclusão e as ações inclusivas tornam-se pouco visíveis nas políticas de avaliação e nos índices de desempenho. 
Concordo com Guizzotti (2016, p. 571) quando afirma que "esforços disciplinares isolados, iniciativas sem objetivos claros, atendimento às outras exigências externas, administrativas comparativas ou classificatórias de unidades ou sistemas escolares comprometem o propósito formativo da avaliação do aluno em classe". Assim, é essencial que a avaliação, seja da aprendizagem escolar ou a externa, funcione como uma alavanca, garantindo o direito de aprender e a qualidade do ensino e da aprendizagem. A presença de estudante com deficiência no sistema educacional é um fator que gera movimento, no sentido de desestabilizar estruturas padronizadas, dentre elas algumas práticas de avaliação.

\section{Considerações finais}

Para finalizar, saliento a perspectiva foucaultiana, que atravessou este texto:

Uma postura que se caracteriza pela mais completa e permanente desconfiança sobre as verdades que se costuma tomar como dadas, tranquilas e naturais. Uma postura que se manifesta pelas constantes tentativas de escapar de qualquer enquadramento que postule como não problemáticas as ideias iluministas de um sujeito fundante, de uma razão transcendental e de um homem ou mulher natural e universal que habitaria dentro de cada um de nós (VEIGA-NETO, 2011, p. 243).

Os estudos permitem concluir que o encontro com os sujeitos da inclusão gera distintas interpretações. Na lógica neoliberal, há um forte apelo aos discursos inclusivos, e os professores predominantemente os assumem como necessários para a construção de uma sociedade melhor e tornam-se parceiros do Estado no compromisso de efetivar as políticas de inclusão. Os docentes procuram responder favoravelmente à expectativa disseminada de que gerenciem a própria formação, preparem-se para atuar com a diversidade, apresentada como um rico mosaico que representa ganhos a todos.

A inclusão, como sinônimo de acesso, é comemorada pelas estatísticas educacionais. Porém, a inclusão entendida como direito à aprendizagem, parece estar, predominantemente, sob a responsabilidade dos docentes, que se ressentem da falta de conhecimentos específicos, e, influenciados pela ideia da própria incompetência, sentem-se inclinados a amenizar e diferenciar critérios e ressignificar a avaliação. $\mathrm{O}$ reconhecimento da competência docente passa pela capacidade de trazer o "anormal" para a normalidade. 
O processo de avaliação na escola inclusiva impõe muitos desafios aos docentes, dentre eles, aprender com a diferença, apropriar-se de tecnologias assistivas, organizar distintamente espaços e tempos, reinterpretar a escola de educação básica e a universidade, as formas de aprender, de ensinar e de ser professor. Os professores descobrem a pluralidade da inclusão, passando a compreendê-la como uma palavra multifacetada, que provoca tensionamentos, desassossegos, mas também que mobiliza e desconstrói olhares padronizados. Em que pese a ambivalência da inclusão, ela precisa ser comemorada. Os aspectos legais não dão conta desse processo, mas movimentam a sociedade para explorar cenários que já foram escondidos, negados. Pessoas com deficiência existem! Saíram dos hospícios, dos mosteiros, da "Nave dos Loucos" (Narrenschiff), das instituições especializadas.

Dissonante dessa forma de ser e conceber o mundo, a educação especial nos mostra que precisamos "do outro", nos mostra a incompletude, que não está necessariamente nos sujeitos denominados deficientes, mas na condição humana. A avaliação da aprendizagem como estratégia de submissão, classificação, hierarquização, punição, culpabilização, disciplinamento precisa dar lugar à avaliação que diagnostica a contribui para a aprendizagem e o desenvolvimento.

A inclusão de forma genérica, muitas vezes romanceada, silenciada, romantizada, merece ser tensionada para que o sujeito da inclusão, suas necessidade e singularidades ganhem o espaço necessário, desobrigando-o da classificação, da normatização e da normalização. A avaliação classificatória deve para dar lugar à avaliação que diagnostica, que acolhe e mobiliza para a formação de pessoas melhores, não só nos aspectos conceituais, mas também prodecimentais e atitudinais, seja na escola, seja nas demais esferas sociais.

\section{REFERÊNCIAS}

AMARAL, Ligia Assumpção. Pensar a diferença/deficiência. Brasília: Corde, 1994.

BEYER, Hugo Otto. Inclusão e avaliação na escola: de alunos com necessidades educacionais especiais. 4 ed. Porto Alegre: Mediação, 2013.

BRASIL. Presidência da República. Casa Civil. Subchefia para Assuntos Jurídicos. Lei $n^{\circ}$ 10.861, de 14 de abril de 2004. Institui o Sistema Nacional de Avaliação da Educação Superior - SINAES e dá outras Providências. Disponível em: <http://www.planalto.gov.br/ccivil_03/_ato2004-2006/2004/lei/110.861.htm> Acesso em: 30 jun. 2017. 
BRASIL. Ministério da Educação. Educação Inclusiva: Atendimento Educacional Especializado para a Deficiência mental. Brasília, MEC/SEEP, 2005.

BRASIL. Ministério da Educação. Secretaria de Educação Especial. Política Nacional de Educação Especial na Perspectiva da Educação Inclusiva. 2008. Disponível em: $<$ http://portal.mec.gov.br/index.php?option=com_docman\&view=download\&alias=166 90-politica-nacional-de-educacao-especial-na-perspectiva-da-educacao-inclusiva05122014\&Itemid=30192> . Acesso em: 30 jun. 2017.

BRASIL. Ministério da Educação. Portaria nº 867, de 4 de julho de 2012. Institui o Pacto Nacional pela Alfabetização na Idade Certa e as ações do Pacto e define suas diretrizes gerais. Diário Oficial [da] República Federativa do Brasil. Brasília, DF, 5 jul. 2012, seção I, p. 23. Disponível em:

<http://download.inep.gov.br/educacao_basica/provinha_brasil/legislacao/2013/portaria _n867_4julho2012_provinha_brasil.pdf $>$. Acesso em: 30 jun. 2017.

BRASIL. INEP. Censo da educação superior de 2013. Sinopses Estatísticas da Educação Superior - Graduação, 2015. Disponível em: <http://inep.gov.br/sinopsesestatisticas-da-educacao-superior>. Acesso em: 24 out. 2015.

BRASIL. Presidência da República. Casa Civil. Lei no 13.005 de 25 de junho de 2014. Aprova o Plano Nacional de Educação - PNE e dá outras providências. Diário Oficial [da] República Federativa do Brasil, Brasília, DF, 2014a. Disponível em:

<http://fne.mec.gov.br/images/doc/pne-2014-20241.pdf>. Acesso em: 20 jul. 2014.

BRASIL. Sinaes. Conaes. INEP. Diretoria de Avaliação da Educação Superior. Instrumento de avaliação institucional externa: subsidia os atos de credenciamento, recredenciamento e transformação da organização acadêmica (presencial). Brasília, DF, 2014b.

BRASIL. INEP. Diretoria de Avaliação da Educação Superior. Instrumento de avaliação de cursos de graduação presencial e a distância. Brasília, DF, 2015.

CHIZZOTTI, Antonio. Políticas públicas: direito de aprender e avaliação formativa. Práxis Educativa, Ponta Grossa, v. 11, n. 3, p. 561-576, set./dez., 2016.

CUNHA, Maria Isabel da. Políticas públicas e docência na universidade: novas configurações e possíveis alternativas. In: CUNHA, Maria Isabel da. I. Formatos avaliativos e concepção de docência (Org.). Campinas: Autores Associados, 2005. p. 69-91. (Coleção Educação contemporânea)

ESTRELA, Maria Teresa. Ética e pedagogia no ensino superior. In: LEITE, Carlinda (Org.). Sentidos da pedagogia no ensino superior. Portugal: CIIE/Livpsic, 2010. p. 11-28. (Coleção Ciências da Educação, 7)

FISCHER, Rosa Maria Bueno. Foucault e a análise do discurso em educação. Cadernos de pesquisa, Porto Alegre, n. 114, p. 197-223, nov. 2001. 
FOUCAULT, Michel. Vigiar e punir: nascimento da prisão. Tradução de Raquel Ramalhete. 20. ed. Petrópolis: Vozes, 1999.

GALLO, Sílvio. Repensar a educação: Foucault. Educação \& Realidade, Porto Alegre, v. 29, n. 1, p. 79-97, jan./jun., 2004.

IBGE - Instituto Brasileiro de Geografia e Estatística. Censo demográfico 2010: características gerais da população, religião e pessoas com deficiência. Rio de Janeiro, 2012. Disponível em:

<http://biblioteca.ibge.gov.br/visualizacao/periodicos/94/cd_2010_religiao_deficiencia. pdf>. Acesso em: 14 abr. 2014.

INEP - Instituto Nacional de Estudos e Pesquisas Educacionais Anísio Teixeira. SAEB. 2017. Disponível em: <http://portal.inep.gov.br/educacao-basica/saeb>. Acesso em: 08 nov. 2017.

ITARD, Jean. Relatório II - Relatório feito a Sua Excelência o Ministro do Interior sobre os novos desenvolvimentos e o estado atual do Selvagem do Aveyron. In: BANKS-LEITE, Luci.; GALVÃO, Izabel (Orgs.). A educação de um selvagem: as experiências pedagógicas de Jean Itard. São Paulo: Cortez, 2000. p. 179-229.

LOPES, Maura Corcini. Políticas de inclusão e governamentalidade. Educação \& Realidade, Porto Alegre, v. 34, n. 2, 2009, p. 153-170.

MENEZES, Eliana da Costa Pereira de. A maquinaria escolar na produção de subjetividades. 2011. 189f. Tese (Doutorado em Educação) - Universidade do Vale do Rio dos Sinos, São Leopoldo, 2011.

PIECZKOWSKI, Tania Mara Zancanaro. Inclusão de estudantes com deficiência na educação superior: efeitos na docência universitária. 2014. 208f. Tese (Doutorado em Educação) - Universidade Federal de Santa Maria, Santa Maria, 2014.

SANTOS, Mônica Pereira dos. Perspectiva histórica do movimento integracionista na Europa. Revista Brasileira de Educação Especial, Piracicaba, n. 3, p. 21-29, 1995.

TIFFIN, John; RAJASINGHAM, Lalita. A universidade virtual e global. Tradução de Vinícius Figueira. Porto Alegre: Artmed, 2007.

VEIGA-NETO, Alfredo; LOPES, Maura Corcini. Inclusão e governamentalidade. Revista Educação e Sociedade, Campinas, v. 28, n. 100-Especial, p. 947-963, 2007.

VEIGA-NETO, Alfredo. Neoliberalismo, império e políticas de inclusão: problematizações iniciais. In: RECHICO, Cinara Franco.; FORTES, Vanessa Gadelha. (Org.), A educação e a inclusão na contemporaneidade. Boa Vista: UFRR, 2008, p. $11-28$.

VEIGA-NETO, Alfredo. Foucault e educação: outros estudos foucaultianos. In: SILVA, Tomaz Tadeu da (Org.). O sujeito da educação: estudos foucaultianos. 8 ed.

Petrópolis, RJ: Vozes, (Ciências Sociais da Educação), 2011, p. 225-247. 


\section{Como referenciar este artigo}

PIECZKOWSKI, T. M. Z. Avaliação da aprendizagem na educação especial e as influências das políticas nacionais. Revista Ibero-Americana de Estudos em Educação, Araraquara, v. 13, n. 4, p. 1612-1631, out./dez., 2018. E-ISSN: 1982-5587. DOI: 10.21723/riaee.unesp.v13.n4.out/dez.2018.10882

Submetido em: $11 / 01 / 2018$

Aprovado em: 10/05/2018 